\title{
Pemberdayaan Remaja Melalui Budidaya Tanaman Hidroponik Kampung Kertasemboja, Kelurahan Pegambiran, Kota Cirebon
}

\author{
Layaman $^{1 *}$, Nur Aulia Nasichah ${ }^{2}$, Tika Fatichah Hanim ${ }^{3}$ \\ IAIN Syekh Nurjati Cirebon \\ 1e-mail: layaman72@gmail.com \\ 2e-mail: nuraulianasichah171@gmail.com \\ ${ }^{3}$ e-mail: tikakafatichahhanim2018@gmail.com \\ *Corresponding Author
}

\begin{abstract}
ABSTRAK
Kegiatan pengabdian ini di latarbelakangi oleh adanya indikasi kejenuhan siswa/remaja dalam pembelajaran jarak jauh selama pandemi COVID-19. Tujuan dari kegiatan ini adalah Untuk mengalihkan anak-anak remaja dari pergaulan yang negatif yaitu dengan melakukan kegiatan budidaya hidroponik. Teknik pelaksanaan yang digunakan dalam kegiatan pengabdian yaitu observasi, wawancara, dan praktek bersama langsung menanam tanaman sayuran. Hasil dari kegiatan pengabdian ini adalah para remaja di Kampung Kertasemboja menjadi lebih aktif lagi dalam mengikuti kegiatan-kegiatan remaja yang ada, membangun jiwa kewirausahaan remaja dengan menjual hasil panen yang diperoleh.
\end{abstract}

Kata Kunci: Remaja, Pergaulan, Hidroponik

\begin{abstract}
This activity was motivated by an indication of student saturation in distance learning during the COVID-19 pandemic. The purpose of this activity is to divert teenagers from negative associations, namely by carrying out hydroponic cultivation activities. The implementation techniques used in the community service were observation, interview, and practice together directly planting vegetables. The result of this service activity is that the youth in Kertasemboja Village are becoming more active in participating in existing youth activities, building youth entrepreneurial spirit by selling the harvest they get.
\end{abstract}

Keywords: Youth, Association, Hydroponics 


\section{PENDAHULUAN}

Pandemi COVID-19 memberikan dampak pada seluruh segmen kehidupan manusia, tanpa kecuali pendidikan. Banyak negara memutuskan menutup sekolah dari tingkat dasar sampai perguruan tinggi, termasuk Indonesia (Aji, R. H. S. (2020); Dewi, W. A. F. (2020). Pemerintah Indonesia melalui Kementerian Pendidikan dan Kebudayaan memutuskan pembelajaran dilakukan dengan jarak jauh atau daring. Pembelajaran ini diharapkan bisa memutus mata rantai penyebaran Covid-19. Disisi lain pembelajaran daring yang terlalu lama juga memberikan dampak yang kurang baik. Pawicara, R., \& Conilie, M. (2020), meneliti tentang Pembelajaran Daring terhadap Kejenuhan Belajar Mahasiswa. Hasil penelitian menunjukkan bahwa pelaksanaan pembelajaran daring yang terlalu lama mengakibatkan kejenuhan pada mahasiswa. Rinawati, D., \& Darisman, E. K. (2020) melakukan penelitian yang sama, akan tetapi respondennya adalah siswa SMK. Hasil penelitiannya juga menunjukkan hasil yang sama.

Bentuk kejenuhan anak sekolah terhadap pembelajaran daring ini bisa dilihat dari kegiatan mereka selama pembelajaran dari rumah. Dampaknya, pelaksanaan proses pembelajaran jarak jauh (PJJ) tidak sesuai dengan harapan dan berpotensi meningkatkan kenakalan remaja. Selama pandemi muncul banyak kasus, seperti ketika orang tua bekerja anakanak mereka tidak belajar di rumah. Padahal kegiatan sekolah tatap muka belum dilaksanakan, anak-anak sepedaan saat jam belajar. Mereka tidak terkontrol, lebih banyak main handphone yang tidak sesuai dengan peruntukannya.

Anak yang memasuki masa remaja merupakan anak yang perlu dibina dengan baik. Karena pada masa remaja anak-anak sudah memasuki masa pubertas dan mereka mudah sekali terbawa oleh pergaulan di lingkungan sekitarnya. Masa remaja juga berpengaruh terhadap masa depan anak. Peran orang tua pun perlu diperhatikan untuk anak dalam melewati masa remajanya. Perhatian dan kasih sayang yang penuh dari orang tua akan membuat anak remaja tidak mudah mengikuti pergaulan yang kurang baik.

Kenakalan remaja juga dapat digambarkan sebagai kegagalan dalam pemenuhan tugas perkembangan. Beberapa anak gagla dalam mengembangkan control diri yang dimiliki orang lain seusianya selama perkembangan. Menurut Harvigust salah satu tugas perkembangan remaja ialah bertanggung jawab sebagai warga Negara, mencapai tingkah laku yang bertanggung jawab social, serta berkembang dalam pemaknaan nilai-nilai yang ada di masyarakat (Aroma \& Suminar, 2012).

Factor penyebab kenakalan anak-anak remaja yaitu anak kurang mendapat perhatian dan kasih sayang serta tuntutan pendidikan dari orang tuanya, kebutuhan psikis dan fisik anak-anak 
remaja yang tidak terpenuhi, anak tidak mendapatkan latihan tentang disiplin dan control diri yang baik (Sumara, Humaedi, \& Santoso, 2017).Sebagai orang tua kita harus bisa meminimalisir factor penyebab kenakalan anak-anak remaja tersebut.

Perhatian untuk para anak remaja tidak hanya dari orang tua dan keluarga saja, tetapi masyarakat sekitar atau lingkungan sekitar pun perlu memberikan perhatian kepada anak-anak remaja. Karena, lingkungan sekitar pun dapat membentuk pribadi dari seorang anak remaja. Kondisi social lebih menekankan kepada lingkungan sekitar anak berada (Tricahyani \& Widiasavitri, 2016). Apabila di lingkungan sekitar itu pergaulan remajanya baik maka seorang remaja pun akan terbawa baik. Sedangkan, kalau lingkungan sekitar tidak baik dalam masalah pergaulan remaja, kemungkinan besar remaja tersebut akan terbawa arus yang tidak baik. Sebagai orang tua dan masyarakat sekitar, kita perlu membentuk pergaulan di kalangan remaja menjadi baik, seperti mengadakan kegiatan positif bagi anak remaja agar para remaja tidak mudah dan tidaak dipengaruhi oleh kegiatan yang negative.

Salah satu kegiatan yang dapat mengalihkan anak-anak remaja dari pergaulan yang negative adalah dengan budidaya hidroponik. Hidroponik adalah lahan budidaya pertanian tanpa menggunakan media tanam tanah, sehingga hidroponik menggunakan air sebagai media tanamannya. Tanaman hidroponik lebih aman dikonsumsi, karena tanaman ini tidak memerlukan pestisida untuk mengusir hama-hama yang ada. Jenis tanaman yang cocok untuk hidroponik adalah tanaman sayur-sayuran seperti selada dan pakcoy. Hal ini dikarenakan tanaman sayuran tidak mempunyai batang yang besar sehingga tidak berat ketika di tanam di hidroponik (Roidah, 2014). Dengan memanfaatkan lahan yang ada, budidaya hidroponik menjadi alternatif untuk mengisi waktu luang.Hal ini juga bisa di aplikasikan kepada anak-anak remaja yang tidak memiliki kesibukan serta untuk meningkatkan kreatifitas.

Dalam berhidroponik, terdapat 10 (sepuluh) system hidroponik (Bertaniorganik, 2018): pertama, Wick System. Sistem Wick adalah sistem yang paling sederhana. Disebut juga sistem pasif dengan kondisi air menggenang, yang berarti tidak ada bagian yang bergerak. Larutan nutrisi ditarik ke dalam media tumbuh dari wadah nutrisi dengan sumbu, biasanya sumbu yang digunakan berupa kain flannel atau jenis bahan lain yang mudah menyerap air. Berbagai media dapat digunakan dalam Sistem wick, sekam bakar, rockwool, perlite/vermikulit, atau dapat pula menggunakan hidroton juga zeolit. Kelemahan terbesar dari sistem ini adalah jika tanaman besar dan menggunakan air lebih banyak dari daya serap sumbu. Sedangkan dalam prosesnya meliputi, semai, pindah tanam ke sistem wick, perawatan dan panen. 


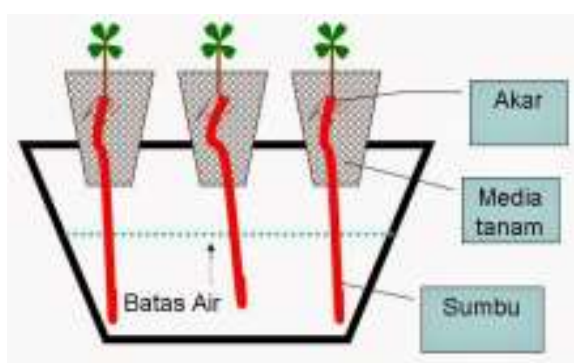

Gambar 1. Wick System

Kedua, NFT (Nutrient Film Technique) System. Prinsip dari system ini adalah tanaman tumbuh pada lapisan nutrisi yang dangkal dan tersirkulasi sehingga tanaman dapat memperoleh cukup air, nutrisi dan oksigen.

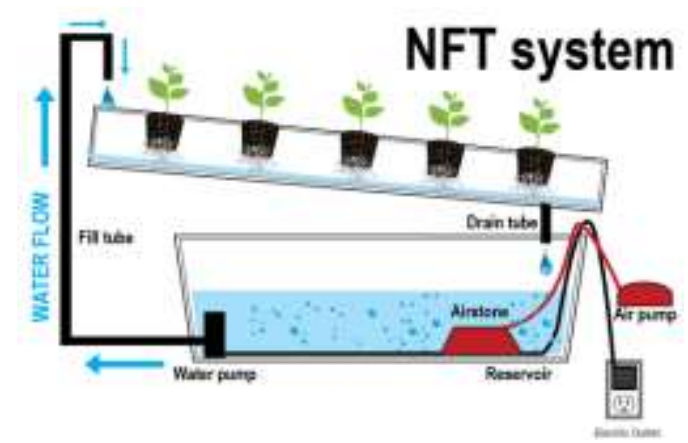

Gambar 2. NFT (Nutrient Film Technique) System

Ketiga, Water Culture System atau sistem kultur air statis merupakan sistem hidroponik sederhana berikutnya. Sistem hidroponik ini bekerja dengan cara menggenangi tanaman dengan air bercampur larutan nutrisi. Sebagai tempat meletakan tanaman biasanya digunakan papan styrofoam yang juga berfungsi untuk menahan tanaman agar dapat mengapung, sehingga sistem ini juga disebut sistem rakit apung. Selain itu, untuk menyuplai oksigen digunakan pompa air yang membuat gelembung pada larutan nutrisi yang kemudian menyuplai oksigen ke akar tanaman. Water Culture System sangat bagus diterapkan pada jenis tanaman yang memerlukan banyak air dan akar yang tenggelam seperti bayam atau kangkung.

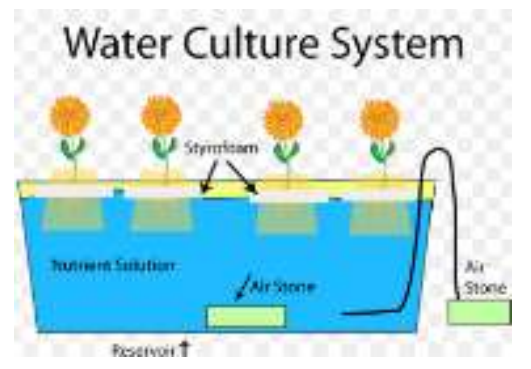

Gambar 3. Water Culture System 
Keempat, EBB \& flow system. Sistem ini disebut juga dengan sistem pasang surut karena tanaman mendapatkan air, nutrisi, dan oksigen dari proses pemompaan bak penampung yang nantinya akan membasahi akar tanaman. Saat air naik membasahi akar inilah disebut pasang seperti halnya air pantai yang sedang naik. Beberapa waktu kemudian air dan nutrisi akan kembali lagi ke bak penampungan atau disebut dengan istilah surut. Nah terjadinya proses pasang surut ini diatur menggunakan timer yang disesuaikan dengan kebutuhan tanaman sehingga tanaman tidak akan tergenang atau kekurangan air.

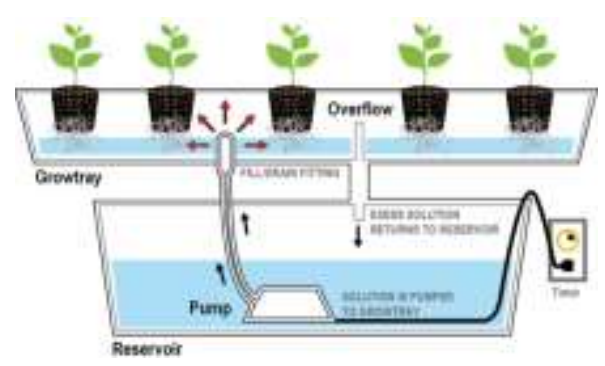

Gambar 4. EBB \& flow system

Kelima, Drip sistem atau disebut juga sistem tetes merupakan teknik hidroponik dengan cara meneteskan larutan nutrisi secara terus menerus ke dalam media tanam melalui pipa atau selang. Larutan nutrisi ditampung di dalam wadah atau tandon air kemudian dihubungkan dengan menggunakan selang yang terhubung dengan media tanam lalu air dipompa hingga membentuk tetesan-tetesan pada media tanam. Sistem ini membutuhkan energi listrik dan pompa. Tanaman mendapatkan nutrisi dari setiap tetesan yang ada. Sehingga tanaman tidak menggenang air maupun tidak mengalami kekeringan. Waktu atau timer juga digunakan dalam tetesan ini, sehingga lebih efektif untuk anda yang sibuk atau tidak sempat memberikan air nutrisi.

Drip System

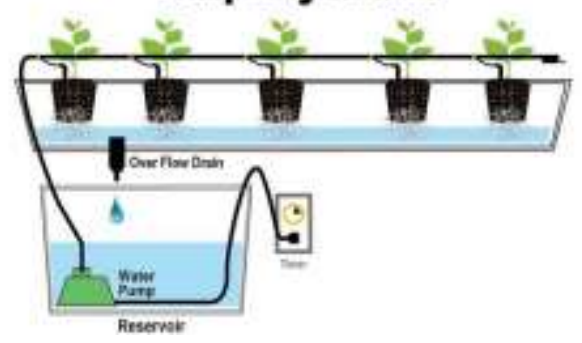

Gambar 5. Drip sistem

Keenam, Aeroponics System. Sistem Aeroponics ini Air dan nutrisi yang akan diserap tanaman diberikan dalam bentuk butiran kecil atau kabut. Pengkabutan ini berasal dari pompa dari bak penampungan yang disemprotkan menggunakan nozzel sehingga nutrisi yang diberikan akan lebih cepat terserap akar tanaman. 


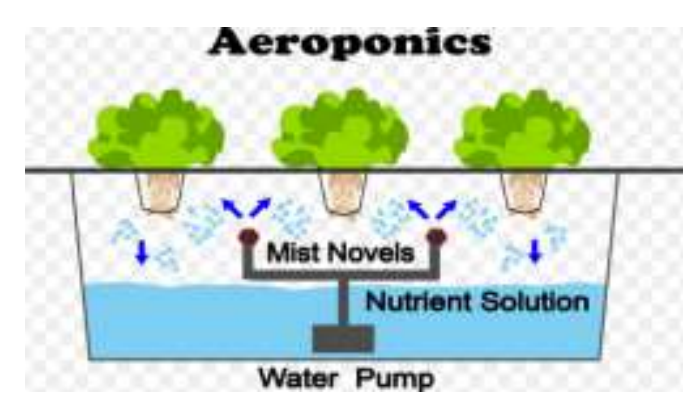

\section{Gambar 6 Aeroponics System}

Ketujuh, Bubbleponics (Sistem Gelembung). Metode tanaman hidroponik yang dikenal sebagai Deep Water Culture yaitu menumbuhkan tanaman secara mengambang diatas larutan nutrisi. Tanaman ditahan menggunakan jaring dengan akar tanaman didalam air. Larutan nutrisi aliri gelembung udara yang memperkaya oksigen dalam larutan yang berguna bagi akar untuk tumbuh. Pada masa awal pertumbuhan akar, larutan nutrisi dipompakan melalui pembentuk gelembung untuk memperkaya kandungan oksigen di dalam larutan yang terbukti membantu pertumbuhan akar dari tanaman. Inilah yang dikenal sebagai metode Bubbleponic.

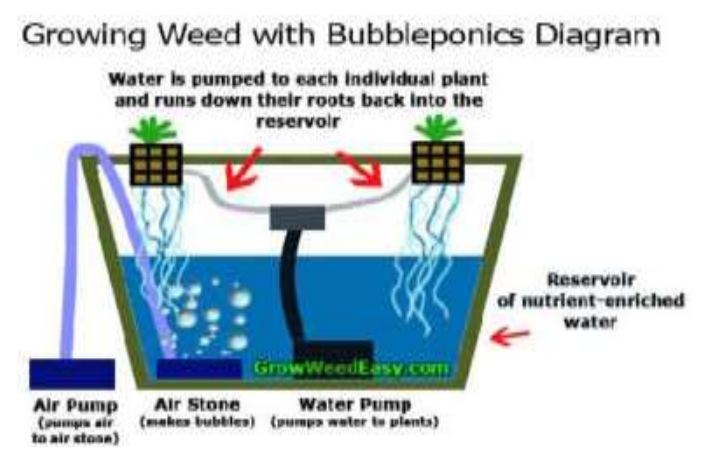

\section{Gambar 7. Bubbleponics (Sistem Gelembung)}

Kedelapan, DFT Sistem (Deep Flow Technique) adalah cara menanam tanaman dengan mensirkulasikan larutan nutrisi tanaman secara terus-menerus selama 24 jam pada rangkaian aliran tertutup. Larutan nutrisi tanaman di dalam tangki dipompa oleh pompa air menuju bak penanaman melalui jaringan irigasi pipa, kemudian larutan nutrisi tanaman di dalam bak penanaman dialirkan kembali menuju tangki.

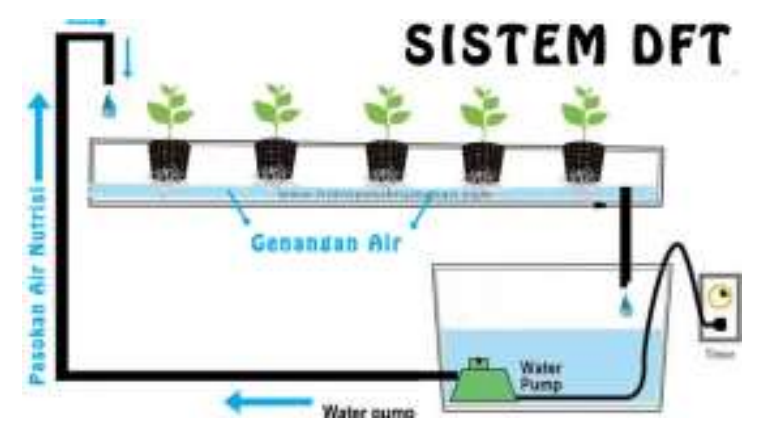

Gambar 8. DFT Sistem (Deep Flow Technique) 
Kesembilan, Sistem Fertigasi. Sistem fertigasi tanaman hidroponik adalah teknik aplikasi yang menggunakan unsur hara melalui sistem irigasi. Fertigasi merupakan singkatan dari fertilisasi atau (pemupukan) dan irigasi. Dalam menggunakan teknik fertigasi biaya untuk pemupukan dapat dikurangi, karena pupuk diberikan bersamaan dengan penyiraman. Selain itu, peningkatan efisiensi penggunaan unsur hara karena pupuk diberikan dalam jumlah sedikit tetapi kontinyu; serta mengurangi kehilangan unsur hara (khususnya nitrogen) akibat leaching atau pencucian dan denitrifikasi (kehilangan nitrogen akibat perubahan menjadi gas).

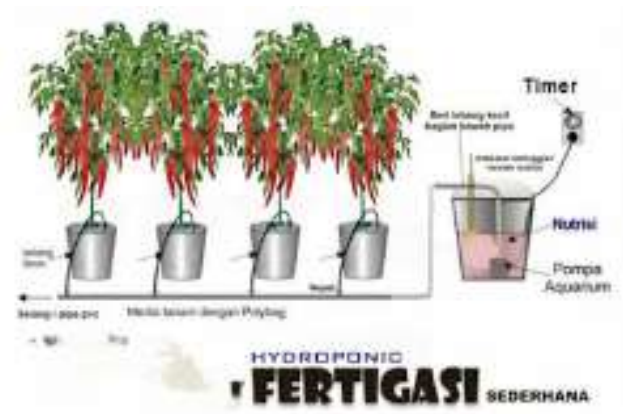

\section{Gambar 9. Sistem Fertigasi}

Kesepuluh, Bioponic. Metode tanam bioponik merupakan metode budidaya tanaman hybrid yang menggabungkan antara sistem tanam hidroponik dengan sistem pertanian organik. Metode ini ditemukan untuk mengatasi masalah-masalah dan menggabungkan keuntungan dari dua metode tanam tersebut. Jadi, metode bioponik adalah sistem hidroponik yang menggunakan nutrisi organik yang berasal dari bahan-bahan alami.

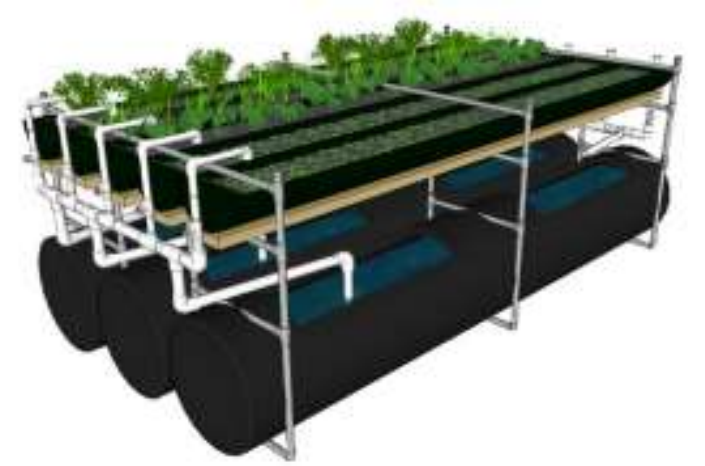

Gambar 10. Bioponic system

\section{BAHAN DAN METODE}

Kegiatan pengabdian ini dilaksanakan pada tanggal 01-31 Juli 2020 di Rw 13 Kampung Kertasemboja, Kelurahan Pegambiran, Kecamatan Lemahwungkuk, Kota Cirebon. Pelaksanaan pengabdian ini menggunakan pendekatan partisipatif dan kualitatif dalam mengumpulkan data, dan diolah menjadi sebuah deskripsi atau narasi. Teknik pelaksanaan yang digunakan dalam 
kegiatan pengabdian yaitu observasi, wawancara, dan praktek langsung terhadap anak-anak remaja yang ada di Kampung Kertasemboja. Observasi dilakukan untuk mengetahui pergaulan yang ada di Kampung Kertasemboja dan mencari kegiatan yang akan dilakukan untuk mengembangkan anak-anak remaja. Wawancara dilakukan untuk mengetahui pendapat serta alasan para remaja dalam kegiatan yang dilakukan. Sedangkan praktek langsung, ditujukan untuk mengajak dan memberikan contoh kepada anak-anak remaja yang ada di Kampung Kertasemboja untuk lebih aktif lagi.

\section{HASIL DAN PEMBAHASAN}

Hidroponik adalah sistem budidaya pertanian yang dilakukan secara vertikal atau bertingkat, baik dalam ruangan maupun diluar ruangan dengan media utama air (Mas'ud, 2009). Sistem budidaya pertanian secara hidroponik ini merupakan konsep penghijauan yang cocok untuk daerah perkotaan dan lahan terbatas (Tom, 2005). Murali et al. (2011) juga menyampaikan bahwa dilihat dari sisi ekonomi, menanam sayuran dengan konsep Hidroponik sangat menguntungkan. Tanpa membutuhkan biaya yang tinggi dan dengan perawatan yang relatif mudah, warga bisa memenuhi kebutuhan sayur mayur sehat tanpa harus membeli (Purwasih, R., 2019).

Berdasarkan hasil pengamatan yang dilakukan di Kampung Kertasemboja terhadap pergaulan anak-anak remaja, menunjukkan bahwa pergaulan yang terjadi di Kampung Kertasemboja ini ada yg positif dan ada juga yang negative. Dapat dilihat dari cukup banyaknya remaja yang ada di Kampung Kertasemboja serta kegiatan yang yang ada, tetapi hanya sedikit anak remaja yang ikut berpasrtisipasi. Kegiatan yang ada juga sebenarnya sudah di fasilitasi oleh pihak Kampung, tetapi belum digunakan secara optimal.

Berdasarkan permasalahan yang ada di Kampung Kertasemboja, peneliti ingin mengajak anak-anak remaja untuk mengikuti kegiatan positif serta ingin megaktifkan kembali kegiatan yang ada agar anak-anak remaja di Kampung Kertasemboja mempunyai kesibukan dan terhindar dari pergaulan yang negative. Kegiatan yang mendukung untuk mengubah pergaulan remaja guna membangun Kampung yaitu budidaya tanaman hidroponik.

Tanaman hidroponik menggunakan media tanam air, sehingga dalam perawatannya tidak terlalu sulit seperti budidaya tanaman yang menggunakan media tanam tanah. Kegiatan hidroponik ditujukan untuk melatih kreativitaas para anak-anak remaja yang ada di Kampung Kertasemboja dan mengisi waktu luang sehingga naka remaja bisa terhindar dari pergaulan yang negative. Selama masa covid-19 banyak anak-anak remaja yang menghabiskan waktunya hanya dirumah saja tanpa melakukan kegiatan apapun. Kegiatan hidroponik ini merupakan salah satu 
cara untuk melatih para anak-anak remaja lebih kreatif dengan menjual hasil dari hidroponik. Adanya hidroponik para remaja bisa belajar untuk budidaya sayuran yang nantinya bisa mereka jual.

Budidaya hidroponik di Kampung Kertasemboja menggunakan NFT (Nutrient Film Technique) System. Teknik ini dimulai dengan menyiapkan lahan dan instalasi hidroponik dari pipa paralon. Pada bagian pipa paralon dibuat lubang untuk menaruh pot tanaman hidroponik. Instalasi hidroponik dibuat bertahap penempatannya agar air tetap mengalir dengan baik. Kemudian dibagian bawah instalasi disediakan drum yang dijadikan tempat untuk air yang akan dialirkan ke instalasi.

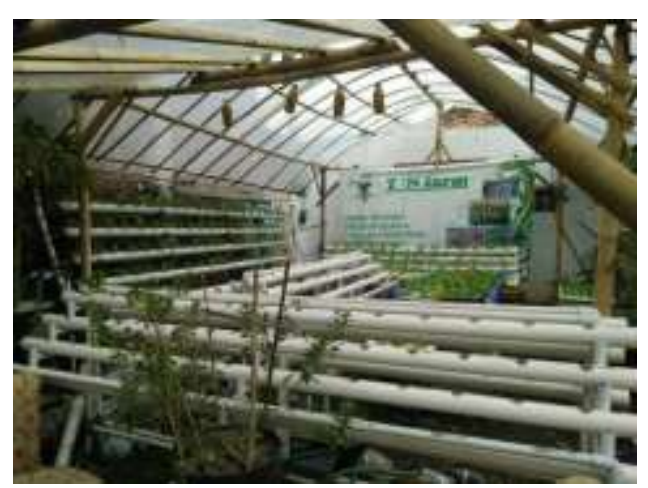

Gambar 11. Instalasi Hidroponik

Pemilihan bibit tanaman yang akan ditanam pada instalasi hidroponik juga perlu diperhatikan. Tanaman yang cocok untuk hidroponik adalah tanaman yang tidak mempunyai batang besar. Biasanya tanaman yang ditanam adalah jenis sayur-sayuran. Karena ketika panen, sayur tersebut bisa dikonsumsi dan lebih baik daripada sayuran yang ditanam di tanah. Sayuran yang biasanya ditanam di hidroponik yaitu pakcoy, selada air, serta samhong (sejenis sawi hijau). Tanaman yang akan ditanam di hidroponik kali ini adalah sayur jenis pakcoy. Bibit tanaman pakcoy akan ditanam terlebih dahulu dengan media busa atau arang sekam, tidak langsung ke dalam instalasi hidroponik. Ukuran busa atau arang sekam yang digunakan sekitar $2 \times 2 \mathrm{~cm}$ saja, dan bagian tengah dilubangi untuk menaruh bibit tanaman. Kemudian bibit tanaman yang sudah ada ditaruh ditempat seperti nampan yang sudah diberi air dan nutrisi yang dibutuhkan oleh tanaman pakcoy. Biarkan bibit tanaman ini di dalam nampan selama 10 hari. Setelah 10 hari bibit tanaman tersebut dipindahkan kedalam pot dan selanjutnya diletakkan di instalasi hidoponik. Nutrisi yang dibutuhkan tanaman pakcoy ini harus lebih dari 1.100 . 


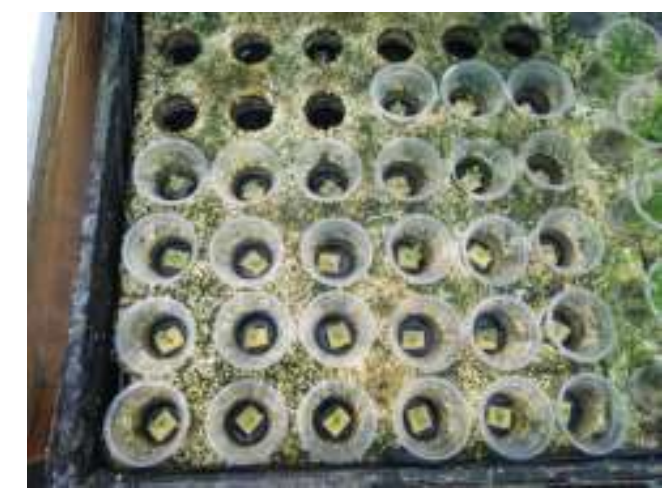

Gambar 12. Bibit tanaman hidroponik

Perawatan yang diberikan untuk tanaman hidroponik tidaklah sulit. Tanaman hidroponik hanya memerlukan pengecekan yang rutin selama pertumbuhannya. Nutrisi yang cukup akan membuat tanaman tumbuh sesuai dengan usianya. Apabila dalam pertumbuhannya nutria yang diberikan kurang, maka daun-daun dari sayuran pakcoy tersebut akan berubah menjadi kuning. Pada pagi hari diusahakan nutrisi selalu dicek agar terhindar dari daun-daun yang menguning dan tumbuh dengan subur. Tidak hanya itu, setiap pagi juga air yang ada di instalasi diaduk agar nutrisi bisa tercampur dengan rata. Selain memantau nutrisi yang dibutuhkan, memantau tanaman dari serangan hama pun perlu dilakukan. Hama pada tanaman hidroponik biasanya datang pada malam hari. Maka dari itu, setiap malam harus selalu dilakukan pengecekan tanaman dari hama. Biasanya hama yang ada pada tanaman hidroponik ini adalah ulat atau belalang. Tidak perlu menggunakan pestisida dalam mengusir hama yang ada, hanya perlu diambil saja hama tersebut dari bagian tanaman.

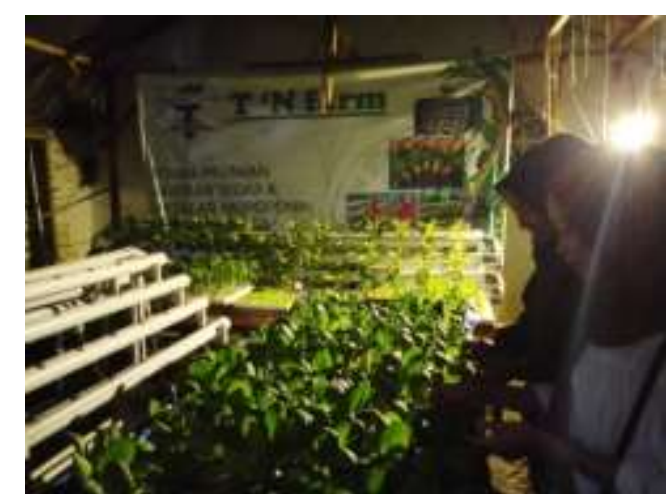

\section{Gambar 13. Pengecekan hama pada malam hari}

Jangka waktu yang dibutuhkan sayur pakcoy untuk dipanen adalah 4 minggu. Setelah 4 minggu tanaman pakcoy ini sudah siap dipanen karena umurnya yang memang sebentar.Panen pada hidroponik sangatlah mudah dan tidak membutuhkan waktu yang lama. Hanya dengan mencabut atau mengambil sayuran pakcoy tersebut dari pot, tanaman tersebut sudah bisa diolah.Panen yang dilakukan bisa pada malam hari atau pagi hari. 


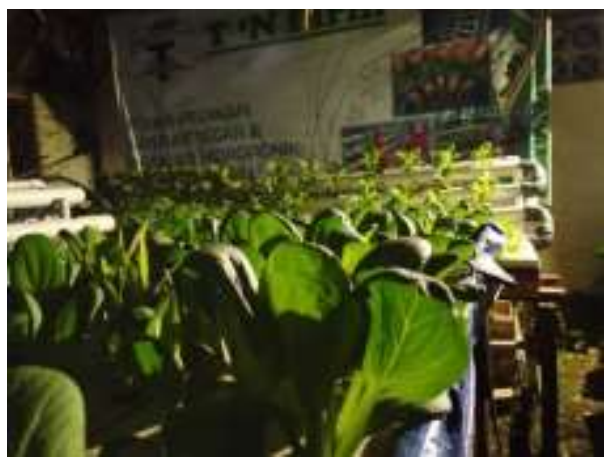

Gambar 14. Sayur pakcoy yang siap dipanen

Beberapa kelebihan tanaman dengan sistem hidroponik ini (Izzuddin, A., 2016), antara lain : 1) Ramah lingkungan karena tidak menggunakan pestisida atau obat hama yang dapat merusak tanah, menggunakan air hanya 1/20 dari tanaman biasa, dan mengurangi CO2 karena tidak perlu menggunakan kendaraan atau mesin. 2) Tanaman ini tidak merusak tanah karena tidak menggunakan media tanah dan juga tidak membutuhkan tempat yang luas. 3) Bisa memeriksa akar tanaman secara periodik untuk memastikan pertumbuhannya. 4) Pemakaian air lebih efisien karena penyiraman air tidak perlu dilakukan setiap hari sebab media larutan mineral yang dipergunakan selalu tertampung di dalam wadah yang dipakai. 5) Hasil tanaman bisa dimakan secara keseluruhan termasuk akar karena terbebas dari kotoran dan hama. 6) Lebih hemat karena tidak perlu menyiramkan air setiap hari, tidak membutuhkan lahan yang banyak, media tanaman bisa dibuat secara bertingkat. 7) Pertumbuhan tanaman lebih cepat dan kualitas hasil tanaman dapat terjaga. 8) Bisa menghemat pemakaian pupuk tanaman. 9) Tidak perlu banyak tenaga kerja. 10) Lingkungan kerja lebih bersih. 11) Tidak ada masalah hama dan penyakit tanaman yang disebabkan oleh bakteri, kulat dan cacing nematod yang banyak terdapat dalam tanah. 12) Dapat tanam di mana saja bahkan di garasi dan tanah yang berbatu. Dan 13) Dapat ditanam kapan saja karena tidak mengenal musim.

Kegiatan hidoponik ini sangat bermanfaat sekali bagi remaja-remaja di Kampung Kertasemboja dalam mengisi waktu luang mereka. Selain itu, kegiatan ini merupakan sarana untuk membangun kebersamaan diantara anak-anak remaja. Hasil panen yang cukup banyak bisa menjadi peluang bisnis bagi remaja. Mereka bisa menjualkan hasil panen tersebut kepada masyarakat sekitar. Hal ini dapat mengembangkan kreatifitas anak remaja dalam berdagang.

Kegiatan positif untuk para remaja di Rw 13 Kampung Kertasemboja sangat penting untuk di dukung dan diberi perhatian lebih. Karena dengan adanya kegiatan yang positif remajaremaja yang ada bisa terhindar dari pergaulan yang negative atau tidak baik. Dapat dilihat juga dengan adanya kegiatan pengabdian ini, remaja yang sebelumnya kurang aktif dalam kegiatan remaja menjadi lebih aktif untuk ikut serta dalam kegiatan. Pihak masyarakat pun perlu 
memantau dan memberikan perhatian khusus untuk para remaja agar memilih pergaulan yang baik.

\section{KESIMPULAN}

Kegiatan pengabdian ini berpengaruh terhadap pergaulan remaja. Dengan adanya kegiatan ini para remaja di Kampung Kertasemboja menjadi lebih aktif lagi dalam mengikuti kegiatan-kegiatan remaja yang ada. Salah satu kegiatan positif yang dilakukan adalah budidaya tanaman hidroponik. Budidaya hidroponik tidaklah membutuhkan lahan yang besar serta waktu yang banyak. Kegiatan ini dapat membangun rasa kebersamaan antar para remaja serta dapat mengembangkan kreatifitas anak-anak remaja. Selain itu, kegiatan ini juga membangun jiwa kewirausahaan remaja dan dapat mengalihkan para remaja dari pergaulan negative yang ada. Budidaya hidroponik pun tidak terlalu sulit untuk dilakukan para remaja, karena hanya dengan pengecekan nutrisi dan serangan hama, tanaman hidroponik dapat tumbuh dengan baik. Hasil panen yang diperoleh dapat menjadikan peluang bagi remaja dalam bisnis berdagang. Adanya kegiatan ini para remaja lebih aktif dan dapat terhindar dari pergaulan yang negative.

\section{UCAPAN TERIMA KASIH}

Ucapan terima kasih diucapkan kepada Rw 13 Kampung Kertasemboja, Kelurahan Pegambiran, Kecamatan Lemahwungkuk, Kota Cirebon yang telah banyak mendukung berjalannya program pengabdian ini.

\section{DAFTAR PUSTAKA}

Aji, R. H. S. (2020). Dampak Covid-19 pada Pendidikan di Indonesia: Sekolah, Keterampilan, dan Proses Pembelajaran. Salam: Jurnal Sosial dan Budaya Syar-i.(7), 5, 395-402.

Aroma, I. S., \& Suminar, D. R. (2012). Hubungan Antara Tingkat Kontrol Diri Dengan Kecenderungan Perilaku Kenakalan Remaja. Jurnal Psikologi Pendidikan Dan Perkembangan, 1(2).

Bertaniorganik, “10 Macam Sistem Hidroponik Yang Sering Digunakan,” 28 Juli 2018. [Online]. Available: http://www.bertaniorganik.com/2018/07/28/10-macam-sistem-hidroponikyang-sering-digunakan/.

Dewi, W. A. F. (2020). Dampak Covid-19 terhadap implementasi pembelajaran daring di Sekolah Dasar. Edukatif: Jurnal Ilmu Pendidikan, 2(1), 55-61.

Izzuddin, A. (2016). Wirausaha Santri Berbasis Budidaya Tanaman Hidroponik. Jurnal Pengabdian Masyarakat/DIMAS, 12(2), 351-366. 
Mas'ud, H. 2009. Sistem Hidroponik dengan Nutrisi dan Media Tanam Berbeda Terhadap Pertumbuhan dan Hasil Selada. Media Litbang Sulteng. 2 (2), 131- 136

Murali, M.R., Soundaria, M., Maheswari, V., Santhakumari, P., Gopal, V. 2011. Hydroponics, a novel alternative for geoponic cultivation of medicinal plants and food crops. International Journal Pharmacy and Biology Science, 2(2), 286-296.

Pawicara, R., \& Conilie, M. (2020). Analisis Pembelajaran Daring terhadap Kejenuhan Belajar Mahasiswa Tadris Biologi IAIN Jember di Tengah Pandemi Covid-19. ALVEOLI: Jurnal Pendidikan Biologi, 1(1), 29-38.

Purwasih, R. (2019). Pemanfaatan lahan pekarangan untuk budi daya sayuran secara hidroponik di Kecamatan Sungailiat, Kabupaten Bangka, Provinsi Kepulauan Bangka Belitung. Agrokreatif: Jurnal Ilmiah Pengabdian kepada Masyarakat, 5(3), 195-201.

Rinawati, D., \& Darisman, E. K. (2020). Survei tingkat kejenuhan siswa SMK belajar di rumah pada mata pelajaran produk kreatif dan kewirausahaan selama masa pandemi covid-19. Journal of Science and Education (JSE), 1(1), 32-40.

Roidah, I. S. (2014). Pemanfaatan Lahan Dengan Menggunakan Sistem Hidroponik. Jurnal Universitas Tulungagung BONOROWO, 1(2). Retrieved from file://C:/Users/ASUS/Downloads/14-22-1-SM.pdf

Sumara, D., Humaedi, S., \& Santoso, M. B. (2017). Kenakalan Remaja dan Penanganannya. Jurnal Penelitian \& PPM, 4(2), 129-389.

Tom, T. 2005. Garden History : Philosophy and Design, 2000 BC--2000 AD. Spon Press; New York.

Tricahyani, I. A. R., \& Widiasavitri, P. N. (2016). Hubungan Antara Dukungan Sosial Dengan Penyesuaian Diri Pada Remaja Awal di Panti Asuhan Kota Denpasar. Jurnal Psikologi Udayana, 3(3), 542-550. 